\title{
A Genome Scan to Detect Quantitative Trait Loci for Economically Important Traits in Holstein Cattle Using Two Methods and a Dense Single Nucleotide Polymorphism Map
}

\author{
H. D. Daetwyler, ${ }^{1}$ F. S. Schenkel, M. Sargolzaei, and J. A. B. Robinson \\ Centre for Genetic Improvement of Livestock, Department of Animal and Poultry Science, University of Guelph, Guelph, \\ Ontario, Canada N1G 2W1
}

\section{ABSTRACT}

Genome scans for detection of bovine quantitative trait loci (QTL) were performed via variance component linkage analysis and linkage disequilibrium single-locus regression (LDRM). Four hundred eighty-four Holstein sires, of which 427 were from 10 grandsire families, were genotyped for 9,919 single nucleotide polymorphisms (SNP) using the Affymetrix MegAllele GeneChip Bovine Mapping 10K SNP array. A hybrid of the granddaughter and selective genotyping designs was applied. Four thousand eight hundred fifty-six of the 9,919 SNP were located to chromosomes in basepairs and formed the basis for the analyses. The mean polymorphism information content of the SNP was 0.25. The SNP centimorgan position was interpolated from their base-pair position using a microsatellite framework map. Estimated breeding values were used as observations, and the following traits were analyzed: 305-d lactation milk, fat, and protein yield; somatic cell score; herd life; interval of calving to first service; and age at first service. The variance component linkage analysis detected 102 potential QTL, whereas LDRM analysis found 144 significant SNP associations after accounting for a $5 \%$ false discovery rate. Twenty potential QTL and 49 significant SNP associations were in close proximity to QTL cited in the literature. Both methods found significant regions on Bos taurus autosome (BTA) 3, 5, and 16 for milk yield; BTA 14 and 19 for fat yield; BTA 1, 3, 16, and 28 for protein yield; BTA 2 and 13 for calving to first service; and BTA 14 for age at first service. Both approaches were effective in detecting potential QTL with a dense SNP map. The LDRM was well suited for a first genome scan due to its approximately 8 times lower computational demands. Further fine mapping should be applied on the chromosomal regions of interest found in this study.

Received May 3, 2007.

Accepted April 9, 2008

${ }^{1}$ Corresponding author: hans.daetwyler@roslin.ed.ac.uk
Key words: dairy cattle, genome scan, quantitative trait loci, single nucleotide polymorphism

\section{INTRODUCTION}

Traditional methods of genetic improvement in livestock species have relied solely on phenotype and pedigree information. The discovery of genetic markers has made it possible to detect regions of the genome that are significantly associated with differences in the expression of a phenotype such as milk production, socalled QTL. Genetic response can be improved by including the QTL in marker-assisted selection, which is a method of selection that makes use of phenotypic, genotypic, and pedigree data (e.g., Smith, 1967). In marker-assisted selection, selection does not occur on the QTL directly, unless the genetic marker is the causal mutation, but on a marker that is linked to the QTL through linkage disequilibrium (LD).

In the past, genotyping many markers was expensive and, therefore, specific experimental designs were developed to reduce the impact of having fewer markers on statistical power. The granddaughter design in dairy cattle made use of sire EBV, which had high precision due to progeny tests, to maximize power with a minimum of genotyped animals (Weller et al., 1990). More recently, however, high throughput methods have been developed to genotype markers such as single nucleotide polymorphisms (SNP), which have significantly reduced the cost. It is currently possible to genotype individuals for $10,000,50,000$, or more SNP with a gene chip array, and the bovine genome can be covered with a dense SNP map to potentially increase the power of association studies.

The QTL detection studies performed to date have found a large number of QTL in dairy cattle for traits of medium to high heritability, such as milk yield and composition traits (e.g., Khatkar et al., 2004; Polineni et al., 2006). Information on QTL that are associated with conformation and functional traits is becoming more readily available (e.g., Schrooten et al., 2000; Ashwell et al., 2005), and traits of lower heritability, such 
Table 1. Descriptive statistics for observations ${ }^{1}$

\begin{tabular}{lcccc}
\hline Trait & EBV $\overline{\mathrm{x}}$ & EBV SD & EBV acc. $\overline{\mathrm{x}}$ & $\%$ acc. $\geq 90.0$ \\
\hline MY & 631 & 773.9 & 94.9 & 91.8 \\
FY & 19 & 28.6 & 94.9 & 91.8 \\
PY & 22 & 22.4 & 94.9 & 91.8 \\
SCS & 3.04 & 0.28 & 92.0 & 90.8 \\
HL & 3.01 & 0.22 & 88.3 & 55.1 \\
CTFS & 0.20 & 5.22 & 91.0 & 63.6 \\
AFS & -1.02 & 8.79 & 92.7 & 84.6 \\
\hline
\end{tabular}

${ }^{1} \mathrm{EBV} \overline{\mathrm{x}}=$ mean estimated breeding value, EBV SD = EBV standard deviation, EBV acc. $\overline{\mathrm{x}}=$ mean EBV accuracy, \% acc. $\geq 90.0=\%$ of bulls with EBV accuracy of 90 or greater, MY = milk yield, FY = fat yield, $\mathrm{PY}=$ protein yield, $\mathrm{SCS}=$ somatic cell score, $\mathrm{HL}=$ herd life, $\mathrm{CTFS}=$ calving to first service, $\mathrm{AFS}=$ age at first service.

as fertility traits, have been successfully mapped for QTL (e.g., Boichard et al., 2003; Kuhn et al., 2003).

The advent of high throughput genotyping technology gives hope to finding more QTL for functional and fertility traits where heritability is usually low. The aim of this study was to use the increased power gained from a dense SNP map and perform scans of the Bos taurus genome to detect potential QTL in traits of medium to low heritability via variance component linkage analysis (VCLA; George et al., 2000) and linkage disequilibrium single locus regression (LDRM; Grapes et al., 2004).

\section{MATERIALS AND METHODS}

\section{Experimental Design}

The experimental design was a hybrid of the granddaughter (Weller et al., 1990) and the selective genotyping (Darvasi and Soller, 1992) designs. Ten Holstein grandsires with sufficiently large groups of progeny tested sons in Canada were chosen. From these 10 families, the lowest and highest 4 to 5 sons were chosen according to their EBV for each of the following 4 traits (305-d lactation protein yield, mammary system, SCS and daughter fertility). Some bulls overlapped across traits, so that the number of bulls resulting from this process was 333 , for a mean of 33 sons per grandsire. In addition, 88 grandsons from 6 of the 10 grandsires, 46 potential sires of sons, and 17 Holstein bulls imported from Europe were added to the analysis. In total, 484 bulls were genotyped and 421 of the bulls were part of the 10 core families. Up to 6 generations of genotyped sires were represented in the data set and the mean inbreeding coefficient of all genotyped bulls was 5.9\%. All the 484 sampled bulls contributed genetically to the current Canadian Holstein cow population.

The data set was checked for stratification between the European and North American bulls by tracing back the pedigrees and by calculating allele frequency correlations between the 17 European sires and a random sample of 17 North American bulls in the data set for all the SNP that showed significant associations with any of the traits analyzed (5,000 replicates). The expected correlation of allele frequencies within only the North American bulls was also calculated from 5,000 random samples of 2 groups of 17 North American bulls.

\section{Observations}

The observations used were EBV obtained from the Canadian Dairy Network, (Guelph, Ontario) from the May 2006 genetic evaluation (Van Doormaal, 2007). Multiple across country evaluation was used, if needed and available, according to the minimum criteria for official bull proofs of the Canadian Dairy Network (2007). The EBV statistics can be found in Table 1 and show that the mean EBV accuracy was high (range $88.3 \%$ to $94.9 \%$ ). The following traits were analyzed: 305-d lactation milk yield (MY), 305-d lactation protein yield (PY), 305-d lactation fat yield (FY), SCS, herd life (HL), interval from calving to first service (CTFS), and age at first service (AFS). Herd life is a measure of longevity expressed as the number of lactations a cow stays in the herd. The CTFS is the period from parturition to first insemination in days, and AFS is the age in days at which a heifer is artificially inseminated for the first time.

\section{Genotype Assays}

Maxxam Analytics Inc. (Guelph, Ontario, Canada) extracted DNA from the semen samples and Affymetrix Inc. (South San Francisco, CA) performed the SNP genotyping via the Affymetrix MegAllele GeneChip Bovine Mapping 10K SNP array (Affymetrix Inc., 2006). Four hundred eighty-four bulls were tested for 9,919 SNP, but 56 bulls failed to produce genotyping results due to possible phenolchloroform contamination. Data were received on 9,628 SNP and of these, 4,856 SNP were physically located to chromosomes (in bp) using the bovine genome sequence (Btau-2.0) obtained from the 
International Bovine Genome Sequencing Consortium (ftp://ftp.hgsc.bcm.tmc.edu/pub/data/Btaurus/fasta/ Btau20050310- freeze/) at the time of this research.

\section{Calculation of SNP Statistics}

Deviation from Hardy-Weinberg equilibrium of the SNP was tested using a chi-square test with one degree of freedom. The departure from random mating, heterozygosity $(\mathbf{H})$ and polymorphism information content (PIC) was also determined. Departure from random mating was calculated as the mean difference between the observed and expected number of heterozygotes under Hardy-Weinberg equilibrium and SNP H was calculated based on observed allele frequencies. The PIC content for the SNP was calculated as shown in Guo and Elston (1999) and was the probability that one can determine if it was the maternal or paternal allele that an offspring has inherited from its parent, assuming no crossover during meiosis.

\section{Building the Linkage Map}

The centimorgan positions for the SNP were interpolated using a microsatellite framework map available from the National Centre for Biotechnology Information, Bethesda, MD (National Centre for Biotechnology Information, 2006). This framework map was edited to allow for interpolation of SNP centimorgan positions. When the marker order between the base-pair and centimorgan maps changed, the crossing microsatellite with a pattern contrary to the other microsatellites in the same section was deleted. All microsatellite markers that had the same base-pair positions or had a centimorgan position of 0.0 were removed. When 2 or more microsatellite markers had the same centimorgan position only the marker with the lowest base-pair position was retained in the framework map. Once both the microsatellite base-pair and linkage map had the same order, the base-pair locations of the SNP were interpolated to centimorgans based on the location within a microsatellite bracket.

\section{Variance Component Linkage Analysis}

Due to the structure of the genotyped population and the complexity of the pedigree information, a REML with variance component estimation was chosen (George et al., 2000). Single-trait analysis was performed on a chromosome-by-chromosome basis. The SNP with a PIC of 0.0 were excluded from the analysis. Using Loki (Heath, 1997), the identical-by-descent (IBD) probabilities were estimated at 1-cM intervals starting at $0.0 \mathrm{cM}$ and ending after the last SNP posi-
Table 2. Descriptive statistic for single nucleotide polymorphisms ${ }^{1}$

\begin{tabular}{|c|c|c|c|}
\hline BTA & Frequency & $\begin{array}{l}\text { BTA length } \\
(\mathrm{cM})\end{array}$ & $\mathrm{SNP} / \mathrm{cM}$ \\
\hline 1 & 257 & 147 & 1.75 \\
\hline 2 & 250 & 120 & 2.08 \\
\hline 3 & 267 & 129 & 2.07 \\
\hline 4 & 202 & 110 & 1.84 \\
\hline 5 & 171 & 132 & 1.30 \\
\hline 6 & 226 & 127 & 1.78 \\
\hline 7 & 177 & 138 & 1.28 \\
\hline 8 & 162 & 121 & 1.34 \\
\hline 9 & 171 & 110 & 1.55 \\
\hline 10 & 217 & 106 & 2.05 \\
\hline 11 & 285 & 127 & 2.24 \\
\hline 12 & 135 & 113 & 1.20 \\
\hline 13 & 174 & 93 & 1.88 \\
\hline 14 & 141 & 92 & 1.54 \\
\hline 15 & 160 & 96 & 1.67 \\
\hline 16 & 203 & 98 & 2.08 \\
\hline 17 & 148 & 110 & 1.35 \\
\hline 18 & 147 & 84 & 1.75 \\
\hline 19 & 144 & 93 & 1.55 \\
\hline 20 & 148 & 76 & 1.96 \\
\hline 21 & 100 & 95 & 1.05 \\
\hline 22 & 149 & 80 & 1.86 \\
\hline 23 & 152 & 71 & 2.13 \\
\hline 24 & 150 & 69 & 2.18 \\
\hline 25 & 126 & 64 & 1.97 \\
\hline 26 & 112 & 75 & 1.50 \\
\hline 27 & 78 & 66 & 1.18 \\
\hline 28 & 94 & 56 & 1.69 \\
\hline 29 & 116 & 69 & 1.68 \\
\hline Mean & 167.66 & 98 & 1.71 \\
\hline
\end{tabular}

${ }^{1} \mathrm{BTA}=$ Bos taurus autosome, $\mathrm{SNP}=$ single nucleotide polymorphism.

tion on a chromosome. Mixing in Loki was improved by setting the LM ratio (proportion of locus versus meiosis updates) to 0.5 (Daw et al., 1999). Two hundred thousand iterations were performed with a burn-in period of 1,000 iterations to achieve satisfactory IBD convergence. If a marker was closer than $0.1 \mathrm{cM}$ to the point where the IBD probability was to be estimated, the IBD matrix sometimes turned out to be singular. In these cases, to avoid singularity, the QTL location was moved to either the right or the left of the original position, so that the minimum distance to the closest SNP was $0.1 \mathrm{cM}$. ASReml (Gilmour et al., 2000) computed the mixed linear models at each IBD location to obtain parameter estimates for the random factors. The full fitted model was

$$
\mathbf{y}=\mu \mathbf{1}+\mathbf{Z}_{\mathbf{1}} \mathbf{a}+\mathbf{Z}_{\mathbf{2}} \mathbf{v}+\mathbf{e}
$$

where $\mathbf{y}$ is a vector of EBV, $\mu$ is the population mean, $\mathbf{Z}_{\mathbf{1}}$ is the incidence matrix for animal effects, $\mathbf{a}$ is a vector of the additive polygenic animal effects, $\mathbf{Z}_{2}$ is the incidence matrix for the QTL effects, $\mathbf{v}$ is a vector of the additive QTL effects, and $\mathbf{e}$ is the vector of residuals. The random effects $\mathbf{a}, \mathbf{v}$, and $\mathbf{e}$ were assumed to be 
independent and normally distributed: $\mathbf{a} \sim N\left(0, \mathbf{A} \sigma_{\mathrm{a}}^{2}\right)$, $\mathbf{v} \sim N\left(0, \mathbf{G} \sigma_{\mathrm{QTL}}^{2}\right)$, and $\mathbf{e} \sim N\left(0, \mathbf{I} \sigma_{\mathrm{e}}^{2}\right)$, where $\mathbf{A}$ is the numerator relationship matrix, $\sigma_{\mathrm{a}}^{2}$ is the variance of the additive polygenic effects, $\mathbf{G}$ is the IBD probability matrix, $\sigma_{\mathrm{QTL}}^{2}$ is the additive QTL variance, $\mathbf{I}$ is the identity matrix, and $\sigma_{\mathrm{e}}^{2}$ is the residual variance. This model was then refitted without the $\mathbf{Z}_{2} \mathbf{v}$ term. The QTL test performed was a likelihood ratio test $(\mathbf{L R})$, where the maximum restricted likelihood of the full model was compared with the maximum restricted likelihood of the model missing the QTL effect. The additive relationship matrix (A) was the same for both models and included all relevant animals in the pedigree (5,615 animals). The sires' EBV were assumed to have equal residual variances, given that most of the bulls had highly accurate proofs (Table 1 ).

\section{Linkage Disequilibrium Single Locus Regression (LDRM)}

A primary $\mathrm{LD}$ screen using regression on individual SNP genotypes was carried out (Grapes et al., 2004). Markers were assumed to be in LD with QTL in close proximity and the effect evaluated was additive only (QTL allele substitution effect). SNP with a minor allele frequency of less than or equal to 0.1 were excluded from the analysis. The following model was calculated at each SNP genotype location using ASReml:

$$
\mathbf{y}=\mathbf{X b}+\mathbf{Z}_{1} \mathbf{a}+\mathbf{e}
$$

with $\mathbf{a} \sim N\left(0, \mathbf{A} \sigma_{\mathrm{a}}^{2}\right)$ and $\mathbf{e} \sim N\left(0, \mathbf{I} \sigma_{\mathrm{e}}^{2}\right)$, where $\mathbf{X}$ is the design matrix in which SNP genotypes were coded 0 , 1 and 2 for 1-1, 1-2, and 2-2 allele combinations, respectively, and $\mathbf{b}$ is the vector of coefficients of the regression on recoded SNP genotypes. As for VCLA, the sires' EBV were assumed to have equal residual variances. Thus regressions were not weighted by the EBV accuracies.

\section{Statistical Inference}

The false discovery rate (FDR; Benjamini and Hochberg, 1995) was used to account for multiple hypotheses testing in both methods. All significance values computed in this study were on a 5\% chromosome-wise FDR level. The significance values for VCLA were obtained from a mix of 2 chi-square distributions (Self and Liang, 1987). In VCLA, due to the nature of FDR, the largest LR in a peak could possibly not be significant at 5\% FDR, whereas positions with a lower LR around it were significant. In those cases, the position with the largest LR was still reported as the peak because FDR is not monotonic with respect to the probability of the test statistic and does not recognize the dependency of the tests. In linkage analysis (LA), the tests for QTL at IBD positions close to each other are likely dependent (Fernando et al., 2004). The $P$-values for the LDRM were taken from a 2 -tailed $t$-test distribution and only SNP below a chromosomal FDR of 5\% were reported.

Confidence intervals were not calculated, as bootstrapping would have been too computationally intensive to carry out. Instead, logarithmic odds scores were computed and 2 QTL on a chromosome were considered distinct if the logarithmic odds score dropped more than one point from the higher peak at a position between the 2 LR peaks.

Potential QTL and significant SNP associations were considered in agreement with QTL cited in the literature if they were within a $95 \%$ confidence interval of a QTL in a published study, or, if such an interval was not available, they were within $5 \mathrm{cM}$ of a QTL position in a published analysis. When comparing the results to previously reported QTL, it is important to recognize that centimorgan locations are relative and depend on the linkage map used in each study. Differences occur because linkage maps are calculated based on the amount of recombination between the genetic makers relative to the first marker evaluated on the chromosome. Therefore, comparisons to literature positions give only a coarse measure of QTL location agreement.

\section{RESULTS}

\section{SNP and Data Set Statistics}

The located SNP were approximately evenly distributed across the genome. Table 2 shows the SNP frequency and density per chromosome. The number of SNP and SNP density per Bos taurus autosome (BTA) varied from 78 to 285 and 1.18 to $2.24 \mathrm{SNP} / \mathrm{cM}$, respectively. Seventeen percent of SNP were not in HardyWeinberg equilibrium at the 5\% significance level and the departure from random mating was 0.04 (SE 0.003), which confirms that positive assortative mating had occurred in the sires' pedigrees. The mean $\mathrm{H}$ for the SNP was 0.31 (range 0.0 to 0.5 ) and per chromosome mean SNP H ranged between 0.26 and 0.35 . The mean PIC was 0.25 (range 0.0 to 0.375 ) and the chromosomes with smallest and largest means were the same as the $\mathrm{H}$ results because $\mathrm{PIC}$ is highly dependent on $\mathrm{H}$. Four hundred thirty-one of the 4,856 SNP in this data set had a PIC of 0.0. These SNP were nonsegregating or fixed, and would not have added any information to the analysis and were therefore removed.

Tracing back of the 17 European bull pedigrees revealed that $86 \%$ of their founders (sires with unknown parents) were of North American origin. Thus, the European bulls were strongly related to the North Ameri- 
Table 3. Potential QTL detected via variance component linkage analysis on Bos taurus autosomes 1 to $8^{1}$

\begin{tabular}{|c|c|c|c|c|}
\hline BTA & $\begin{array}{l}\text { Location } \\
\quad(\mathrm{cM})\end{array}$ & Trait & LR & $\mathrm{FDR}^{2}$ \\
\hline 1 & 79 & PY & 13.8 & - \\
\hline 1 & $109^{3}$ & PY & 9.0 & - \\
\hline 1 & 135 & PY & 9.1 & - \\
\hline 2 & 71 & PY & 11.0 & 0.06 \\
\hline 2 & 105 & CTFS & 11.2 & - \\
\hline 3 & $37^{4}$ & MY & 8.9 & 0.10 \\
\hline 3 & $25^{5}$ & PY & 7.5 & - \\
\hline 3 & $45^{5}$ & PY & 15.3 & - \\
\hline 3 & 41 & SCS & 10.8 & 0.07 \\
\hline 3 & 27 & CTFS & 10.2 & 0.09 \\
\hline 3 & 34 & CTFS & 9.7 & - \\
\hline 3 & 45 & CTFS & 9.1 & - \\
\hline 3 & 68 & CTFS & 4.7 & - \\
\hline 4 & 4 & MY & 4.8 & - \\
\hline 4 & 14 & MY & 7.8 & - \\
\hline 4 & 57 & MY & 4.9 & - \\
\hline 4 & 86 & MY & 9.5 & 0.12 \\
\hline 4 & 16 & PY & 10.7 & 0.06 \\
\hline 4 & 85 & PY & 8.1 & - \\
\hline 4 & 105 & PY & 6.9 & - \\
\hline 5 & 1 & MY & 18.3 & - \\
\hline 5 & 1 & PY & 23.9 & - \\
\hline 5 & 2 & CTFS & 16.3 & - \\
\hline 6 & $25^{6}$ & PY & 11.1 & 0.06 \\
\hline 6 & 98 & PY & 10.5 & - \\
\hline 6 & 50 & CTFS & 9.3 & 0.15 \\
\hline 6 & 59 & AFS & 9.0 & - \\
\hline 6 & 68 & AFS & 14.1 & - \\
\hline 6 & 100 & AFS & 7.6 & - \\
\hline 8 & 0 & PY & 11.1 & - \\
\hline 8 & 38 & PY & 10.7 & - \\
\hline 8 & 53 & PY & 12.3 & - \\
\hline 8 & 85 & PY & 9.3 & - \\
\hline 8 & 122 & PY & 8.1 & - \\
\hline
\end{tabular}

${ }^{1} \mathrm{BTA}=$ Bos taurus autosome, $\mathrm{LR}=$ likelihood ratio test, $\mathrm{MY}=$ milk yield, PY = protein yield, $\mathrm{SCS}=$ somatic cell score, $\mathrm{CTFS}=$ calving to first service, $\mathrm{AFS}=$ age at first service.

${ }^{2} \mathrm{FDR}=$ false discovery rate, reported only if at the peak position FDR was larger than 0.05 .

${ }^{3}$ In agreement with Rodriguez-Zas et al. (2002).

${ }^{4}$ In agreement with Ashwell et al. (2004).

${ }^{5}$ In agreement with Heyen et al. (1999).

${ }^{6}$ In agreement with Viitala et al. (2003).

can bulls. In addition, the mean correlation of allele frequency of significant SNP associations between the European bulls and North American bulls in the data set was 0.85 (range 0.70 to 0.93 ). This was very similar to the allele frequency correlations within the North American bulls of 0.87 (range 0.71 to 0.94 ). These results indicate that population stratification was likely not responsible for the significant results in our study.

\section{Potential Chromosomal Regions of Interest Detected}

The potential QTL found with VCLA, as well as the previous studies that are in agreement, can be seen in Tables 3 to 5 . The VCLA detected a total of 102 potential
Table 4. Potential QTL detected via variance component linkage analysis on Bos taurus autosomes 9 to $16^{1}$

\begin{tabular}{|c|c|c|c|c|}
\hline BTA & $\begin{array}{l}\text { Location } \\
\quad(\mathrm{cM})\end{array}$ & Trait & LR & $\mathrm{FDR}^{2}$ \\
\hline 9 & 8 & PY & 11.8 & - \\
\hline 9 & $75^{3}$ & PY & 9.2 & - \\
\hline 10 & 21 & PY & 5.8 & - \\
\hline 10 & 99 & PY & 15.5 & - \\
\hline 11 & 38 & PY & 6.5 & - \\
\hline 11 & 66 & PY & 10.7 & 0.07 \\
\hline 11 & 72 & PY & 8.9 & - \\
\hline 11 & 96 & PY & 6.3 & - \\
\hline 11 & 95 & CTFS & 11.4 & - \\
\hline 11 & 108 & CTFS & 10.1 & - \\
\hline 12 & 52 & FY & 6.4 & - \\
\hline 12 & $67^{4}$ & FY & 8.4 & 0.21 \\
\hline 12 & 90 & FY & 2.8 & - \\
\hline 13 & 30 & PY & 13.2 & - \\
\hline 13 & $74^{5}$ & PY & 11.8 & - \\
\hline 13 & 20 & CTFS & 13.6 & - \\
\hline 13 & 39 & CTFS & 6.8 & - \\
\hline 13 & 90 & CTFS & 4.7 & - \\
\hline 14 & $3^{6}$ & FY & 8.5 & 0.17 \\
\hline 14 & $22^{7}$ & SCS & 11.1 & - \\
\hline 14 & 53 & SCS & 9.2 & - \\
\hline 14 & 74 & SCS & 6.2 & - \\
\hline 14 & 3 & AFS & 9.0 & 0.13 \\
\hline 14 & 62 & AFS & 5.0 & - \\
\hline 15 & 17 & PY & 4.5 & - \\
\hline 15 & 41 & PY & 10.0 & - \\
\hline 15 & 62 & PY & 11.9 & - \\
\hline 15 & 93 & PY & 7.5 & - \\
\hline 15 & 6 & CTFS & 11.6 & - \\
\hline 15 & 94 & CTFS & 11.0 & - \\
\hline 16 & $86^{4}$ & MY & 11.5 & - \\
\hline 16 & 59 & PY & 7.2 & - \\
\hline 16 & 68 & PY & 9.6 & - \\
\hline 16 & $85^{4}$ & PY & 19.6 & - \\
\hline 16 & 98 & PY & 13.0 & - \\
\hline
\end{tabular}

${ }^{1} \mathrm{BTA}=$ Bos taurus autosome, $\mathrm{LR}=$ likelihood ratio test, $\mathrm{MY}=$ milk yield, $\mathrm{FY}=$ fat yield, $\mathrm{PY}=$ protein yield, $\mathrm{SCS}=$ somatic cell score, CTFS = calving to first service, AFS = age at first service.

${ }^{2} \mathrm{FDR}=$ false discovery rate, reported only if at the peak position FDR was higher than 0.05 .

${ }^{3}$ In agreement with Georges et al. (1995).

${ }^{4}$ In agreement with Rodriguez-Zas et al. (2002).

${ }^{5}$ In agreement with Ashwell et al. (2004).

${ }^{6}$ In agreement with Khatkar et al. (2004).

${ }^{7}$ In agreement with Zhang et al. (1998).

QTL, including 15 for MY, 6 for FY, 52 for PY, 4 for SCS, 20 for CTFS, and 5 for AFS. Twenty of these QTL were in agreement with QTL previously reported in the literature, including 4 for MY, 4 for FY, 11 for PY, and 1 for SCS. New potential QTL were found for MY (11), FY (2), PY (41), SCS (3), CTFS (20), and AFS (5).

The LDRM found 144 significant SNP associations, which are reported in Tables 6 to 8 . When there were more than one SNP within a 1-cM bracket they were grouped together and the maximum absolute t-value is reported. The number of significant SNP associations found per trait was: 31 for MY, 7 for FY, 22 for PY, 32 
Table 5. Potential QTL detected via variance component linkage analysis on Bos taurus autosomes 17 to $29^{1}$

\begin{tabular}{|c|c|c|c|c|}
\hline BTA & $\begin{array}{l}\text { Location } \\
\quad(\mathrm{cM})\end{array}$ & Trait & LR & $\mathrm{FDR}^{2}$ \\
\hline 18 & 0 & MY & 10.1 & - \\
\hline 18 & 13 & MY & 6.2 & 0.19 \\
\hline 18 & $41^{3}$ & MY & 7.9 & - \\
\hline 18 & 84 & MY & 5.7 & - \\
\hline 18 & 0 & PY & 3.9 & - \\
\hline 18 & 41 & PY & 9.8 & - \\
\hline 18 & 65 & PY & 8.4 & - \\
\hline 18 & $84^{3}$ & PY & 15.5 & - \\
\hline 19 & 36 & MY & 16.2 & - \\
\hline 19 & 60 & MY & 10.9 & - \\
\hline 19 & $36^{4}$ & FY & 11.3 & - \\
\hline 19 & $51^{4}$ & FY & 7.8 & - \\
\hline 19 & 29 & PY & 20.3 & - \\
\hline 19 & 59 & PY & 7.1 & - \\
\hline 23 & $7^{5}$ & MY & 10.3 & - \\
\hline 23 & 6 & PY & 10.4 & - \\
\hline 23 & $26^{4}$ & PY & 5.7 & - \\
\hline 23 & $42^{4}$ & PY & 7.5 & 0.08 \\
\hline 24 & 7 & PY & 7.1 & - \\
\hline 24 & 53 & PY & 11.6 & - \\
\hline 24 & 54 & CTFS & 9.4 & 0.08 \\
\hline 25 & 51 & MY & 11.2 & - \\
\hline 25 & $47^{5}$ & PY & 9.0 & - \\
\hline 25 & 52 & PY & 13.8 & - \\
\hline 25 & 64 & PY & 6.5 & - \\
\hline 25 & 57 & CTFS & 9.0 & 0.09 \\
\hline 26 & 11 & CTFS & 7.6 & - \\
\hline 26 & 72 & CTFS & 7.8 & 0.19 \\
\hline 28 & 1 & PY & 8.1 & - \\
\hline 28 & 11 & PY & 8.5 & 0.10 \\
\hline 28 & 35 & PY & 6.0 & - \\
\hline 29 & 8 & CTFS & 8.4 & 0.13 \\
\hline 29 & 20 & CTFS & 4.0 & - \\
\hline 29 & 60 & CTFS & 4.1 & - \\
\hline
\end{tabular}

${ }^{1} \mathrm{BTA}=$ Bos taurus autosome, $\mathrm{LR}=$ likelihood ratio test, $\mathrm{MY}=$ milk yield, $\mathrm{FY}=$ fat yield, $\mathrm{PY}=$ protein yield, $\mathrm{CTFS}=$ calving to first service.

${ }^{2} \mathrm{FDR}$ = false discovery rate, reported only if at the peak position FDR was higher than 0.05 .

${ }^{3}$ In agreement with Olsen et al. (2002).

${ }^{4}$ In agreement with Bennewitz et al. (2003).

${ }^{5}$ In agreement with Viitala et al. (2003).

for SCS, 17 for HL, 14 for CTFS, and 21 for AFS. As was the case with VCLA, a proportion of the positions, 48 of the $140 \mathrm{SNP}$, were in agreement with previous findings. These SNP included 23 for MY, 2 for FY, 14 for PY, and 9 for SCS. The individual literature studies can be found in the footnotes of Tables 6 to 8 . New significant SNP associations were found in the respective traits: 8 for MY, 5 for FY, 8 for PY, 23 for SCS, 17 for HL, 14 for CTFS and 21 for AFS. Several SNP were associated with phenotypic variation in both MY and PY and this could likely be explained by large genetic correlations between the 2 traits. The direction (positive versus negative) of the regression coefficients was in all cases the same if one SNP had a significant association with differences in phenotype for both traits.
The total number of potential QTL and significant SNP associations found per trait and method of analysis are summarized in Table 9. This table also lists the number of BTA on which both methods found significant associations and agreement between the 2 methods was greatest for the milk production traits and less for SCS and HL.

\section{DISCUSSION}

\section{Choice of Dependent Variable}

The EBV were used as the dependent variable in both VCLA and LDRM. Previous studies have found that using EBV instead of daughter yield deviations or deregressed EBV either does not significantly reduce power (Israel and Weller, 1998) or only slightly reduces power (Thomsen et al., 2001). The potential for EBV to cause a downward bias was decreased by the high mean EBV accuracy in this study (Table 1).

The EBV were not weighted in the analysis to account for accuracy because mean EBV accuracy was high and the potential increase in power would have been minimal. The extent to which EBV are regressed toward zero decreases as the amount of information available to calculate the EBV increases. Thus, EBV of bulls with lower accuracy have a smaller variance than the EBV of bulls with higher accuracy (Israel and Weller, 1998). Bulls with EBV of lower accuracy would therefore have less impact on the results, and this would mitigate the potential for causing bias when not weighting EBV. However, this might not be the case for daughter yield deviations and de-regressed EBV, because bulls with EBV of lower accuracy would de-regress more and potentially might influence the results to a larger extent.

\section{Variance Component Linkage Analysis}

The VCLA method located 102 potential QTL. The relatively large number of new QTL found was promising. The great efficiency of QTL detection for protein yield (52 potential QTL) could be partly explained by the fact that this was one of the traits used for selective genotyping. Whereas the selective genotyping approach seemed to have shown benefits for protein yield QTL, it has not shown an equally strong performance in SCS, where only 4 QTL were called significant. No potential QTL were found for HL with VCLA, which was possibly due to a lower mean EBV accuracy of HL (Table 1). The improved QTL detection in SCS over HL might have been because of the greater precision of SCS EBV, the minor selective genotyping carried out, and because SCS EBV were available for all bulls genotyped, which was not the case for HL. It was also encouraging that for CTFS and AFS, 20 and 5 potential QTL were found, 
Table 6. Significant single nucleotide polymorphism associations from linkage disequilibrium single locus regression analysis on Bos taurus autosomes 1 to $6^{1}$

\begin{tabular}{|c|c|c|c|c|c|}
\hline BTA & $\begin{array}{l}\text { Location } \\
\quad(\mathrm{cM})\end{array}$ & Trait & $\begin{array}{l}\text { No. of } \\
\text { SNP }\end{array}$ & $\begin{array}{c}\text { Max. } \\
\text { |t-value| }\end{array}$ & $\underset{\left(r^{2}\right)}{\text { Mean }}$ \\
\hline 1 & $47^{3}$ & MY & 1 & 3.5 & \\
\hline 1 & $142^{4}$ & MY & 1 & 4.0 & \\
\hline 1 & 140 & FY & 1 & 3.7 & \\
\hline 1 & $47^{5}$ & PY & 1 & 3.5 & \\
\hline 1 & 142 & PY & 1 & 3.8 & \\
\hline 1 & $131^{5}$ & SCS & 4 & 4.3 & 0.86 \\
\hline 1 & 140 & AFS & 1 & 3.7 & \\
\hline 2 & $109^{6}$ & SCS & 1 & 3.7 & \\
\hline 2 & 24 & CTFS & 1 & 4.4 & \\
\hline 3 & $50^{3}$ & MY & 1 & 3.8 & \\
\hline 3 & $50^{5}$ & PY & 1 & 3.4 & \\
\hline 3 & 103 & PY & 1 & 3.5 & \\
\hline 4 & 32 & SCS & 1 & 3.9 & \\
\hline 5 & 3 & MY & 1 & 3.4 & \\
\hline 5 & 77 & SCS & 2 & 3.6 & 0.83 \\
\hline 5 & 86 & SCS & 1 & 3.8 & \\
\hline 5 & 51 & AFS & 1 & 3.4 & \\
\hline 5 & 78 & AFS & 2 & 3.0 & $\mathrm{NA}^{2}$ \\
\hline 5 & 82 & AFS & 2 & 3.5 & 0.84 \\
\hline 6 & 52 & SCS & 1 & 3.0 & \\
\hline 6 & 72 & SCS & 1 & 4.2 & \\
\hline 6 & 73 & SCS & 1 & 2.9 & \\
\hline 6 & 74 & SCS & 1 & 3.4 & \\
\hline 6 & 75 & SCS & 1 & 2.9 & \\
\hline 6 & 78 & SCS & 1 & 2.8 & \\
\hline 6 & 81 & SCS & 1 & 2.8 & \\
\hline 6 & 82 & SCS & 1 & 3.2 & \\
\hline 6 & 83 & SCS & 3 & 3.9 & 0.65 \\
\hline 6 & 46 & HL & 1 & 3.4 & \\
\hline 6 & 51 & HL & 1 & 3.5 & \\
\hline 6 & 53 & HL & 2 & 3.2 & 0.08 \\
\hline 6 & 56 & HL & 1 & 3.1 & \\
\hline 6 & 59 & HL & 1 & 3.6 & \\
\hline 6 & 61 & HL & 1 & 3.2 & \\
\hline 6 & 73 & HL & 1 & 3.1 & \\
\hline 6 & 83 & HL & 2 & 2.9 & 0.19 \\
\hline 6 & 84 & HL & 2 & 2.9 & 0.49 \\
\hline
\end{tabular}

${ }^{1} \mathrm{BTA}=$ Bos taurus autosome, $\mathrm{SNP}=$ single nucleotide polymorphism, $\mathrm{MY}=$ milk yield, $\mathrm{FY}=$ fat yield, $\mathrm{PY}=$ protein yield, $\mathrm{SCS}=$ somatic cell score, $\mathrm{HL}=$ herd life, $\mathrm{CTFS}=$ calving to first service, $\mathrm{AFS}=$ age at first service, mean $\left(\mathrm{r}^{2}\right)=$ mean $\mathrm{r}^{2}$ (linkage disequilibrium) between SNP.

${ }^{2} \mathrm{NA}=\mathrm{r}^{2}$ was not available for these 2 SNP.

${ }^{3}$ In agreement with Khatkar et al. (2004).

${ }^{4}$ In agreement with De Koning et al. (2001).

${ }^{5}$ In agreement with Rodriguez-Zas et al. (2002).

${ }^{6}$ In agreement with Bennewitz et al. (2003).

respectively. The improved result over previous studies in detecting QTL for traits of lower heritability showed that using a dense SNP map can increase power in LA.

\section{Linkage Disequilibrium Regression Method}

The LDRM was successful and a total of 144 significant SNP associations were detected. In traits of low heritability, such as SCS, HL, CTFS, and AFS, the LDRM found a large number of significant SNP associations, which supports LDRM as a viable choice for future genome scans in dairy cattle.
The SNP in very close proximity to each other were often all significantly associated with a particular phenotype. The $\mathrm{r}^{2}$ (Hill and Robertson, 1968) was calculated according to the same guidelines as Sargolzaei et al. (2008) to determine the amount of LD between significant SNP associations within a 1-cM bracket. As can be seen in Tables 6 through 8, in most cases the SNP were in very strong $L D$, and this suggests that they are all associated with the same QTL. However, in some cases the SNP had low LD (e.g., BTA 6, $53 \mathrm{cM}$, $\left.\mathrm{HL}, \mathrm{r}^{2}=0.08\right)$ and may be associated with the same or another QTL. 
Table 7. Significant single nucleotide polymorphism associations from linkage disequilibrium single locus regression analysis on Bos taurus autosomes 7 to $14^{1}$

\begin{tabular}{|c|c|c|c|c|c|}
\hline BTA & $\begin{array}{l}\text { Location } \\
(\mathrm{cM})\end{array}$ & Trait & $\begin{array}{l}\text { No. of } \\
\text { SNP }\end{array}$ & $\begin{array}{c}\text { Max. } \\
\text { |t-value } \mid\end{array}$ & $\begin{array}{c}\text { Mean } \\
\left(\mathrm{r}^{2}\right)\end{array}$ \\
\hline 7 & 60 & MY & 2 & 3.6 & 0.99 \\
\hline 7 & $73^{2}$ & MY & 2 & 3.9 & 0.38 \\
\hline 7 & $75^{2}$ & MY & 1 & 2.9 & \\
\hline 7 & $82^{2}$ & MY & 1 & 3.1 & \\
\hline 7 & 60 & PY & 2 & 3.1 & 0.99 \\
\hline 7 & 68 & PY & 1 & 2.8 & \\
\hline 7 & $73^{2}$ & PY & 2 & 3.5 & 0.38 \\
\hline 7 & $75^{2}$ & PY & 1 & 3.1 & \\
\hline 7 & 95 & PY & 1 & 2.9 & \\
\hline 8 & 101 & FY & 1 & 3.5 & \\
\hline 9 & $57^{3}$ & MY & 2 & 3.4 & 0.58 \\
\hline 9 & 36 & HL & 1 & 3.7 & \\
\hline 9 & 39 & $\mathrm{HL}$ & 1 & 3.7 & \\
\hline 10 & 10 & CTFS & 1 & 3.5 & \\
\hline 10 & 20 & CTFS & 6 & 3.4 & 0.75 \\
\hline 10 & 23 & CTFS & 1 & 2.8 & \\
\hline 10 & 31 & CTFS & 1 & 3.4 & \\
\hline 10 & 42 & CTFS & 1 & 2.8 & \\
\hline 11 & 119 & SCS & 4 & 3.5 & 0.21 \\
\hline 11 & 60 & AFS & 1 & 4.2 & \\
\hline 12 & 59 & MY & 1 & 3.8 & \\
\hline 13 & 63 & HL & 1 & 4.8 & \\
\hline 13 & 35 & CTFS & 1 & 3.4 & \\
\hline 14 & $4^{4}$ & MY & 8 & 4.0 & 0.97 \\
\hline 14 & $5^{4}$ & MY & 1 & 3.3 & \\
\hline 14 & $6^{4}$ & MY & 2 & 3.5 & 0.83 \\
\hline 14 & $12^{5}$ & MY & 3 & 3.3 & 0.75 \\
\hline 14 & 42 & MY & 1 & 3.0 & \\
\hline 14 & $28^{5}$ & FY & 1 & 3.4 & \\
\hline 14 & $4^{5}$ & PY & 4 & 2.9 & 0.95 \\
\hline 14 & $12^{5}$ & PY & 3 & 3.3 & 0.73 \\
\hline 14 & 4 & AFS & 8 & 3.9 & 0.99 \\
\hline 14 & 5 & AFS & 1 & 2.8 & \\
\hline 14 & 6 & AFS & 1 & 2.6 & \\
\hline 14 & 50 & AFS & 1 & 3.0 & \\
\hline 14 & 54 & AFS & 1 & 2.6 & \\
\hline
\end{tabular}

${ }^{1} \mathrm{BTA}=$ Bos taurus autosome, $\mathrm{SNP}=$ single nucleotide polymorphism, MY = milk yield, $\mathrm{FY}=$ fat yield, $\mathrm{PY}=$ protein yield, $\mathrm{SCS}=$ somatic cell score, $\mathrm{HL}=$ herd life, CTFS = calving to first service, AFS = age at first service, mean $\left(r^{2}\right)=$ mean $r^{2}$ (linkage disequilibrium) between SNP.

${ }^{2}$ In agreement with Boichard et al. (2003).

${ }^{3}$ In agreement with Khatkar et al. (2004).

${ }^{4}$ In agreement with Grisart et al. (2004).

${ }^{5}$ In agreement with Bennewitz et al. (2003).

\section{Comparison of Results}

The VCLA method did produce the expected results in locating DGAT (Grisart et al., 2004) at position 3 cM, which is a QTL with a large effect in FY located on chromosome 14 (Khatkar et al., 2004). The LDRM showed a significant SNP association with FY at position $28 \mathrm{cM}$, which is within the confidence interval calculated by Bennewitz et al. (2003) but falls outside of the Khatkar et al. (2004) meta-analysis confidence range. The reason for this suboptimal result of the LDRM may be in the poor SNP distribution at the beginning of chromosome 14 . No SNP were present until 4 $\mathrm{cM}$ on that chromosome, and the LDRM may be more sensitive to gaps in SNP distribution.
Neither VCLA or the LDRM showed conclusive results for the ABCG2 mutation located in the middle of BTA 6 (Cohen-Zinder et al., 2005), which has an effect on MY and composition in Holstein cattle. Whereas VCLA detected 2 protein QTL on BTA 6 , one at 25 $\mathrm{cM}$ and another at $98 \mathrm{cM}$, they were outside of the confidence interval of the meta-analysis for this trait (Khatkar et al., 2004). At the location of the causative mutation identified by Cohen-Zinder et al. (2005) the SNP distribution showed a gap and the LDRM possibly did not overcome that.

In some traits, such as SCS, HL, and AFS, VCLA identified fewer potential regions than did LDRM. While VCLA maps potential QTL, the LDRM detects 
Table 8. Significant single nucleotide polymorphism associations from linkage disequilibrium single locus regression analysis on Bos taurus autosomes 15 to $29^{1}$

\begin{tabular}{|c|c|c|c|c|c|}
\hline BTA & $\begin{array}{l}\text { Location } \\
(\mathrm{cM})\end{array}$ & Trait & $\begin{array}{l}\text { No. of } \\
\text { SNP }\end{array}$ & $\begin{array}{c}\text { Max. } \\
\text { |t-value| }\end{array}$ & $\begin{array}{c}\text { Mean } \\
\left(\mathrm{r}^{2}\right)\end{array}$ \\
\hline 15 & 75 & MY & 1 & 3.3 & \\
\hline 16 & 46 & MY & 1 & 3.5 & \\
\hline 16 & 46 & PY & 1 & 3.5 & \\
\hline 16 & $48^{2}$ & SCS & 1 & 3.5 & \\
\hline 16 & 8 & CTFS & 2 & 4.1 & 0.87 \\
\hline 18 & 50 & AFS & 1 & 3.2 & \\
\hline 19 & $9^{3}$ & FY & 1 & 3.6 & \\
\hline 19 & $47^{3}$ & SCS & 1 & 3.2 & \\
\hline 19 & 58 & HL & 1 & 3.6 & \\
\hline 23 & $52^{4}$ & SCS & 2 & 3.5 & 0.98 \\
\hline 23 & 2 & AFS & 1 & 3.8 & \\
\hline 25 & 55 & SCS & 1 & 3.4 & \\
\hline 26 & $55^{5}$ & MY & 1 & 3.3 & \\
\hline 27 & 28 & SCS & 1 & 3.3 & \\
\hline 28 & 33 & FY & 3 & 3.1 & 0.68 \\
\hline 28 & 45 & FY & 1 & 3.3 & \\
\hline 28 & 48 & FY & 1 & 3.0 & \\
\hline 28 & 33 & PY & 1 & 2.9 & \\
\hline 28 & $44^{2}$ & PY & 1 & 3.1 & \\
\hline 28 & $46^{2}$ & PY & 1 & 3.3 & \\
\hline 29 & 5 & SCS & 1 & 3.1 & \\
\hline 29 & 67 & SCS & 1 & 3.3 & \\
\hline
\end{tabular}

${ }^{1} \mathrm{BTA}=$ Bos taurus autosome, $\mathrm{SNP}=$ single nucleotide polymorphism, $\mathrm{MY}=$ milk yield, $\mathrm{FY}=$ fat yield, $\mathrm{PY}=$ protein yield, $\mathrm{SCS}=$ somatic cell score, $\mathrm{HL}=$ herd life, $\mathrm{CTFS}=$ calving to first service, $\mathrm{AFS}=$ age at first service, mean $\left(r^{2}\right)=$ mean $r^{2}$ (linkage disequilibrium) between SNP.

${ }^{2}$ In agreement with Rodriguez-Zas et al. (2002).

${ }^{3}$ In agreement with Bennewitz et al. (2003).

${ }^{4}$ In agreement with Ashwell et al. (1998).

${ }^{5}$ In agreement with Boichard et al. (2003).

significant SNP associations. Therefore, multiple SNP in close proximity could be in LD with the same QTL. The extent to which not accounting for LD between several SNP and one QTL could have inflated the number of potential significant regions found with the LDRM was investigated. Significant SNP were counted as being in LD with the same QTL when they were within $5 \mathrm{cM}$ of each other (confidence interval $=10 \mathrm{cM}$ ). When counted by this method, 71 significant chromosome regions were found with the LDRM. As can be seen in Table 9, even when grouping SNP into 10-cM groups, the LDRM detected more significant regions in traits of low heritability while finding equivalent or fewer numbers of significant associations in traits of moderate heritability.

Overall, the LDRM discovered a more uniform number of chromosomal regions across traits. There were few BTA on which both methods found significant associations, as can be seen in Table 9. Significant regions for PY that resulted from both methods were found on 4 BTA, which was the most of any trait in this study. The differences in QTL discoveries among the 2 methods are likely related to the sample size that was likely not large enough and limited the power of both approaches, and associated with the inherent differences in the methods with respect to the use of the LD information.

The VCLA utilizes LD within families to calculate IBD probabilities and it is more efficient when the average $\mathrm{r}^{2}$ is low $(<0.2)$, as in the case of low density of markers, compared with LDRM. However, LDRM becomes equally efficient to VCLA when the density of markers increases and the average $r^{2}$ is high (Grapes et al., 2004; Zhao et al., 2006; Goddard and Hayes, 2007). This is because LDRM requires a dense and preferably uniformly distributed marker map, and, if there are gaps with no SNP, the power to detect a QTL diminishes (Grapes et al., 2004). In the current study, whereas the average marker density was 1.7 per cM, there were gaps in the distribution of SNP and differences in SNP density across chromosomes. This could have led to different rates of success in detecting QTL between LDRM and VCLA, depending on the chromosomes, chromosomal regions analyzed, or both. The $\mathrm{r}^{2}$ between SNP differs across genomic regions and chromosomes (Sargolzaei et al., 2008) and could lead to differences between VCLA and LDRM depending on where the QTL were located.

Another option of QTL analysis is to use a combined LD and LA in a LDLA approach (Olsen et al., 2005), 


\section{a) VCLA}

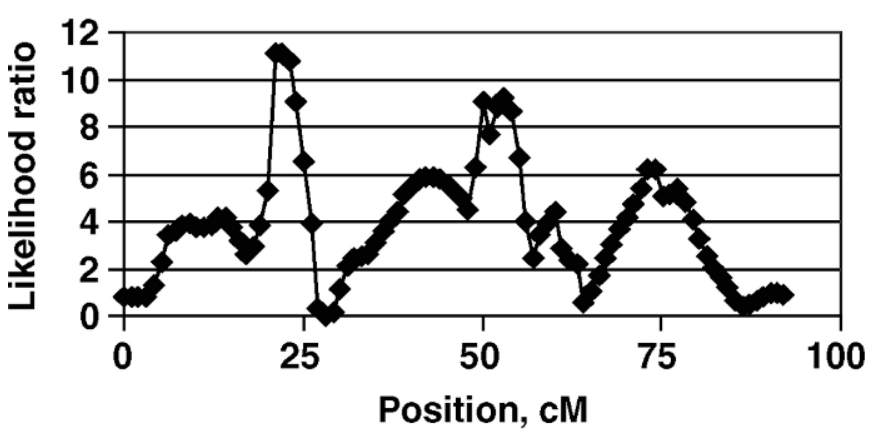

b) LDRM

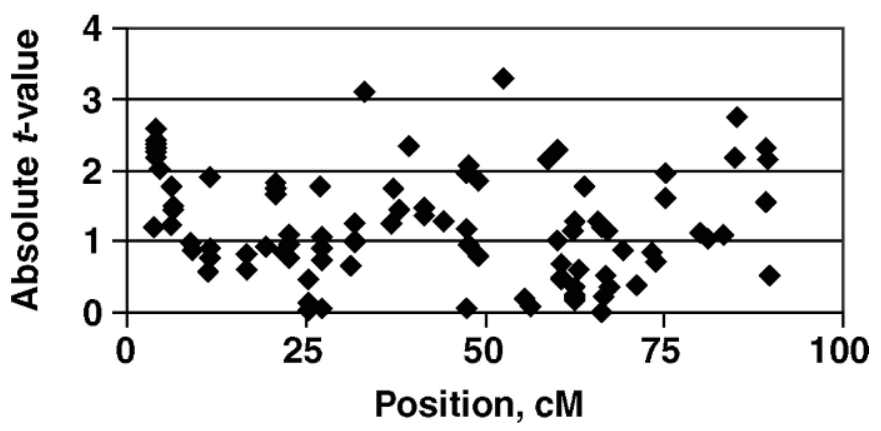

Figure 1. Test statistic profiles for somatic cell score on chromosome 14: a) Variance component linkage analysis (VCLA) likelihood ratio profile and b) Linkage disequilibrium single locus regression (LDRM) absolute $t$-test profile.

which can narrow confidence intervals considerably when compared with LA, but this was beyond the scope of this study.

A LR profile of VCLA and a $t$-test profile representative of the LDRM can be seen in Figure 1. The $t$-test pattern of the LDRM was more erratic than the LR profile of VCLA, which was likely due to the LDRM treating each SNP as a separate regression, whereas in VCLA, all SNP on a chromosome were considered together to calculate IBD at each position. In VCLA, this led to a moderation of the variability in the LR profile. The BTA 14 SCS analyses in Figure 1 also show an example of suggestive unison between the 2 methods even when only one of them showed significant results. Three significant peaks were found with VCLA, but none of the SNP associations were significant in LDRM. However, considering Figure 1b, it is possible to see that the LDRM yielded 3 regions where the SNP have larger $t$-test values, albeit not significant.

The primary focus of this study was on detecting significant chromosome regions for further analysis and not estimating the effects of these regions. In whole genome scans, QTL effects are known to be overestimated, because when the test statistic is maximized over the many point-wise tests in the genome, the estimates of the parameters characterizing the locus-specific effects (e.g., QTL variance) are effectively maximized as well (Göring et al., 2001). Strong evidence was observed for both methods that this was the case in this study (results not shown). Another reason for an upward bias might be the presence of more than 1 QTL in a chromosomal region (Allison et al., 2002), which was not accounted for in the single-QTL analyses performed. In addition, the partial selective genotyping based on 4 traits carried out in this study may have added to the overestimation in some of the analyzed traits.

In LDRM, an effect estimate that was based on few genotypes could have been a source of bias. The SNP with a minor allele frequency of less than or equal to 0.1 (1,441 SNP) were excluded from the analysis for that reason. The most significant $t$-values and effects

Table 9. Total number of significant Bos taurus autosome (BTA) regions found per trait for variance component linkage analysis and linkage disequilibrium single locus regression and the BTA on which both methods found significant associations ${ }^{1}$

\begin{tabular}{lcccc}
\hline & \multicolumn{3}{c}{ Significant BTA regions } & \\
\cline { 2 - 4 } Trait $^{2}$ & VCLA & LDRM & $\begin{array}{c}\text { LDRM } \\
(\text { CI = 10) }\end{array}$ & $\begin{array}{c}\text { Agreement, } \\
\text { VCLA + LDRM }\end{array}$ \\
\hline MY & 15 & 31 & 15 & BTA 3, 5, 16 \\
FY & 6 & 7 & 6 & BTA 14, 19 \\
PY & 52 & 22 & 13 & BTA 1, 3, 16, 29 \\
SCS & 4 & 32 & 15 & - \\
HL & 21 & 17 & 7 & BTA 2, 13 \\
CTFS & 5 & 14 & 6 & BTA 14 \\
AFS & 102 & 21 & 9 & 12 \\
Total & 144 & 71 & \\
\hline
\end{tabular}

${ }^{1} \mathrm{BTA}=$ Bos taurus autosome VCLA = variance component linkage analysis $;$ LDRM = linkage disequilibrium single locus regression; $(\mathrm{CI}=10)=$ number of regions when grouped in 10 -cM intervals.

${ }^{2} \mathrm{MY}=$ milk yield $; \mathrm{FY}=$ fat yield $; \mathrm{PY}=$ protein yield $; \mathrm{HL}=$ herd life $\mathrm{CTFS}=$ calving to first service; $\mathrm{AFS}=$ age at first service. 
were checked for all traits to determine if a possible bias existed, and the minor genotype frequency was never below 0.05 , which corresponds to 23 bulls with this genotype in the SNP investigated. Therefore, this was likely not a large source of bias in this study.

The LDRM had the lesser computational requirement of the 2 methods. The LDRM analyzed 1 chromosome in approximately $0.5 \mathrm{~h}$, whereas VCLA needed an average $4 \mathrm{~h}$, not including IBD calculation time, on a server with $16 \mathrm{~GB}$ of $400 \mathrm{MHz}$ CL3 memory, eight 500-GB SATA disk drives (Iomega, San Diego, CA) and 4 jobs running simultaneously. When computing power or time is limiting, LDRM is more useful than VCLA for a first QTL scan with a dense SNP map.

\section{CONCLUSIONS}

The 2 genome scans resulted in 102 potential QTL and 144 significant SNP associations for production, functional, and reproduction traits in the Holstein dairy sires genotyped. A large number of potential chromosomal regions of interest for traits of low heritability were detected. This study was one of the first applications of the LDRM to dense SNP data, and it showed that the LDRM was capable of detecting significant SNP associations at an average SNP density of 1.7 SNP per cM. The LDRM located more potential chromosomal regions of interest than did VCLA in traits of low heritability. Future work with the LDRM and the full set of SNP marker locations should increase its statistical power.

\section{ACKNOWLEDGMENTS}

The authors thank L'Alliance Boviteq Inc. (SEMEX Alliance, Canada) and the Ontario Centre for Agriculture Genomics (Challenge Fund) for their financial support. We are also grateful for the input of John Woolliams and the 2 anonymous reviewers on this manuscript.

\section{REFERENCES}

Affymetrix Inc. 2006. Affymetrix MegAllele GeneChip Bovine 10K SNP Array. Affymetrix Inc., South San Francisco, CA, Online. http://www.affymetrix.com/support/technical/datasheets/ bovine10k_snp_datasheet.pdf Accessed Oct. 8, 2006.

Allison, D. B., J. R. Fernandez, M. Heo, S. Zhu, C. Etzel, T. M. Beasley, and C. I. Amos. 2002. Bias in estimates of quantitative-trait-locus effect in genome scans: Demonstration of the phenomenon and a method-of-moments procedure for reducing bias. Am. J. Hum. Genet. 70:575-585.

Ashwell, M. S., Y. Da, C. P. Van Tassell, P. M. VanRaden, R. H. Miller, and C. E. Rexroad Jr. 1998. Detection of putative loci affecting milk production and composition, health, and type traits in a United States Holstein population. J. Dairy Sci. 81:33093314 .

Ashwell, M. S., D. W. Heyen, T. S. Sonstegard, C. P. Van Tassell, Y. Da, P. M. VanRaden, M. Ron, J. I. Weller, and H. A. Lewin. 2004.
Detection of quantitative trait loci affecting milk production, health, and reproductive traits in Holstein cattle. J. Dairy Sci. 87:468-475.

Ashwell, M. S., D. W. Heyen, J. I. Weller, M. Ron, T. S. Sonstegard, C. P. Van Tassell, and H. A. Lewin. 2005. Detection of quantitative trait loci influencing conformation traits and calving ease in Holstein-Friesian cattle. J. Dairy Sci. 88:4111-4119.

Benjamini, Y., and T. Hochberg. 1995. Controlling the false discovery rate: A practical and powerful approach to multiple testing. J. R. Stat. Soc. [Ser A] 85:289-300.

Bennewitz, J., N. Reinsch, C. Grohs, H. Leveziel, A. Malafosse, H. Thomsen, N. Xu, C. Looft, C. Kuhn, G. A. Brockmann, M. Schwerin, C. Weimann, S. Hiendleder, G. Erhardt, I. Medjugorac, I. Russ, M. Forster, B. Brenig, F. Reinhardt, R. Reents, G. Averdunk, J. Blumel, D. Boichard, and E. Kalm. 2003. Combined analysis of data from two granddaughter designs: A simple strategy for QTL confirmation and increasing experimental power in dairy cattle. Genet. Sel. Evol. 35:319-338.

Boichard, D., C. Grohs, F. Bourgeois, F. Cerqueira, R. Faugeras, A. Neau, R. Rupp, Y. Amigues, M. Y. Boscher, and H. Leveziel. 2003. Detection of genes influencing economic traits in three French dairy cattle breeds. Genet. Sel. Evol. 35:77-101.

Canadian Dairy Network. 2007. Minimum Criteria for an Official Bull Proof. Canadian Dairy Network Online. http://www.cdn.ca/ document.php?id=6 Accessed Mar. 5, 2007.

Cohen-Zinder, M., E. Seroussi, D. M. Larkin, J. J. Loor, A. Evertsvan der Wind, J. H. Lee, J. K. Drackley, M. R. Band, A. G. Hernandez, M. Shani, H. A. Lewin, J. I. Weller, and M. Ron. 2005. Identification of a missense mutation in the bovine ABCG2 gene with a major effect on the QTL on chromosome 6 affecting milk yield and composition in Holstein cattle. Genome Res. 15:936-944.

Darvasi, A., and M. Soller. 1992. Selective genotyping for determination of linkage between a marker locus and a quantitative trait loci. Theor. Appl. Genet. 85:353-359.

Daw, E. W., S. C. Heath, and E. M. Wijsman. 1999. Multipoint oligogenic analysis of age-at-onset data with applications to Alzheimer disease pedigrees. Am. J. Hum. Genet. 64:839-851.

De Koning, D. J., N. F. Schulman, K. Elo, S. Moisio, R. Kinos, J. Vilkki, and A. Maki-Tanila. 2001. Mapping of multiple quantitative trait loci by simple regression in half-sib designs. J. Anim. Sci. 79:616-622.

Fernando, R. L., D. Nettleton, B. R. Southey, J. C. Dekkers, M. F. Rothschild, and M. Soller. 2004. Controlling the proportion of false positives in multiple dependent tests. Genetics 166:611-619.

George, A. W., P. M. Visscher, and C. S. Haley. 2000. Mapping quantitative trait loci in complex pedigrees: A two-step variance component approach. Genetics 156:2081-2092.

Georges, M., D. Nielsen, M. Mackinnon, A. Mishra, R. Okimoto, A. T. Pasquino, L. S. Sargeant, A. Sorensen, M. R. Steele, and X. Zhao. 1995. Mapping quantitative trait loci controlling milk production in dairy cattle by exploiting progeny testing. Genetics 139:907-920.

Gilmour, A. R., R. Thompson, B. R. Cullis, and S. J. Wellham. 2000. ASReml Reference Manual. NSW Department for Primary Industries, New South Wales, Australia.

Goddard, M. E., and B. J. Hayes. 2007. Genomic selection. J. Anim. Breed. Genet. 124:323-330.

Göring, H. H. H., J. D. Terwilliger, and J. Blangero. 2001. Large upward bias in estimation of locus-specific effects from genomewide scans. Am. J. Hum. Genet. 69:1357-1369.

Grapes, L., J. C. Dekkers, M. F. Rothschild, and R. L. Fernando. 2004. Comparing linkage disequilibrium-based methods for fine mapping quantitative trait loci. Genetics 166:1561-1570.

Grisart, B., F. Farnir, L. Karim, N. Cambisano, J. J. Kim, A. Kvasz, M. Mni, P. Simon, J. M. Frere, W. Coppieters, and M. Georges. 2004. Genetic and functional confirmation of the causality of the DGAT1 K232A quantitative trait nucleotide in affecting milk yield and composition. Proc. Natl. Acad. Sci. USA 101:2398-2403.

Guo, X., and R. C. Elston. 1999. Linkage information content of polymorphic genetic markers. Hum. Hered. 49:112-118.

Heath, S. C. 1997. Markov chain Monte Carlo segregation and linkage analysis for oligogenic models. Am. J. Hum. Genet. 61:748-760. 
Heyen, D. W., J. I. Weller, M. Ron, M. Band, J. E. Beever, E. Feldmesser, Y. Da, G. R. Wiggans, P. M. VanRaden, and H. A. Lewin. 1999. A genome scan for QTL influencing milk production and health traits in dairy cattle. Physiol. Genomics 1:165-175.

Hill, W. G., and A. Robertson. 1968. Linkage disequilibrium in finite populations. Theor. Appl. Genet. 38:226-231.

Israel, C., and J. I. Weller. 1998. Estimation of candidate gene effects in dairy cattle populations. J. Dairy Sci. 81:1653-1662.

Khatkar, M. S., P. C. Thomson, I. Tammen, and H. W. Raadsma. 2004. Quantitative trait loci mapping in dairy cattle: Review and meta-analysis. Genet. Sel. Evol. 36:163-190.

Kuhn, C., J. Bennewitz, N. Reinsch, N. Xu, H. Thomsen, C. Looft, G. A. Brockmann, M. Schwerin, C. Weimann, S. Hiendleder, G. Erhardt, I. Medjugorac, M. Forster, B. Brenig, F. Reinhardt, R. Reents, I. Russ, G. Averdunk, J. Blumel, and E. Kalm. 2003. Quantitative trait loci mapping of functional traits in the German Holstein cattle population. J. Dairy Sci. 86:360-368.

National Centre for Biotechnology Information. 2006. Bovine Microsatellite Framework cM Map. NCBI Online. http://www.ncbi.nlm.nih.gov/mapview/ Accessed May 17, 2006.

Olsen, H. G., L. Gomez-Raya, D. I. Vage, I. Olsaker, H. Klungland, M. Svendsen, T. Adnoy, A. Sabry, G. Klemetsdal, N. Schulman, W. Kramer, G. Thaller, K. Ronningen, and S. Lien. 2002. A genome scan for quantitative trait loci affecting milk production in Norwegian dairy cattle. J. Dairy Sci. 85:3124-3130.

Olsen, H. G., S. Lien, M. Gautier, H. Nilsen, A. Roseth, P. R. Berg, K. K. Sundsaasen, M. Svendsen, and T. H. E. Meuwissen. 2005. Mapping of a milk production quantitative trait locus to a 420 $\mathrm{kb}$ region on bovine chromosome 6. Genetics 169:275-283.

Polineni, P., P. Aragonda, S. R. Xavier, R. Furuta, and D. L. Adelson. 2006. The bovine QTL viewer: A web accessible database of bovine quantitative trait loci. BMC Bioinformatics 7:283.

Rodriguez-Zas, S. L., B. R. Southey, D. W. Heyen, and H. A. Lewin. 2002. Interval and composite interval mapping of somatic cell score, yield, and components of milk in dairy cattle. J. Dairy Sci. 85:3081-3091.

Sargolzaei, M., F. S. Schenkel, G. B. Jansen, and L. R. Schaeffer. 2008. Extent of linkage disequilibrium in Holstein cattle in North America. J. Dairy Sci. 91:2106-2117.
Schrooten, C., H. Bovenhuis, W. Coppieters, and J. A. van Arendonk. 2000. Whole genome scan to detect quantitative trait loci for conformation and functional traits in dairy cattle. J. Dairy Sci. 83:795-806.

Self, S. G., and K. Y. Liang. 1987. Asymptotic properties of maximum likelihood estimators and likelihood ratio tests under nonstandard conditions. J. Am. Stat. Assoc. 82:605-610.

Smith, C. 1967. Improvement of metric traits through specific genetic loci. Anim. Prod. 9:349-358.

Thomsen, H., N. Reinsch, N. Xu, C. Looft, S. Grupe, C. Kuhn, G. A. Brockmann, M. Schwerin, B. Leyhe-Horn, S. Hiendleder, G. Erhardt, I. Medjugorac, I. Russ, M. Forster, B. Brenig, F. Reinhardt, R. Reents, J. Blumel, G. Averdunk, and E. Kalm. 2001. Comparison of estimated breeding values, daughter yield deviations and de-regressed proofs within a whole genome scan for QTL. J. Anim. Breed. Genet. 118:357-370.

Van Doormaal, B. J. 2007. Genetic Evaluation of Dairy Cattle in Canada. Canadian Dairy Network Online. http://cdn.ca/document.php?id=123 Accessed Mar. 5, 2007.

Viitala, S. M., N. F. Schulman, D. J. De Koning, K. Elo, R. Kinos, A. Virta, J. Virta, A. Maki-Tanila, and J. H. Vilkki. 2003. Quantitative trait loci affecting milk production traits in Finnish Ayrshire dairy cattle. J. Dairy Sci. 86:1828-1836.

Weller, J. I., Y. Kashi, and M. Soller. 1990. Power of daughter and granddaughter designs for determining linkage between marker loci and quantitative trait loci in dairy cattle. J. Dairy Sci. 73:2525-2537.

Zhang, Q., D. Boichard, I. Hoeschele, C. Ernst, A. Eggen, B. Murkve, M. Pfister-Genskow, L. A. Witte, F. E. Grignola, P. Uimari, G. Thaller, and M. D. Bishop. 1998. Mapping quantitative trait loci for milk production and health of dairy cattle in a large outbred pedigree. Genetics 149:1959-1973.

Zhao, H. H., J. C. Dekkers, and R. L. Fernando. 2006. Power and precision of regression-based linkage disequilibrium mapping of QTL. Proceedings of the 8th World Congress of Genetics Applied to Livestock Production, Belo Horizonte, Brazil. CD-ROM Publication, 21-20. 